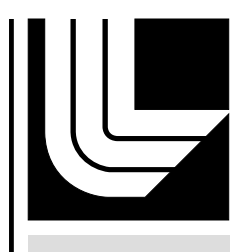

LAW RENCE LIVERMORE N A T IO NAL LABORATORY

INVESTIGATION OF CRUSTAL MOTION IN THE TIEN SHAN USING INSAR

R. J. Mellors

February 28, 2011 
This document was prepared as an account of work sponsored by an agency of the United States government. Neither the United States government nor Lawrence Livermore National Security, LLC, nor any of their employees makes any warranty, expressed or implied, or assumes any legal liability or responsibility for the accuracy, completeness, or usefulness of any information, apparatus, product, or process disclosed, or represents that its use would not infringe privately owned rights. Reference herein to any specific commercial product, process, or service by trade name, trademark, manufacturer, or otherwise does not necessarily constitute or imply its endorsement, recommendation, or favoring by the United States government or Lawrence Livermore National Security, LLC. The views and opinions of authors expressed herein do not necessarily state or reflect those of the United States government or Lawrence Livermore National Security, LLC, and shall not be used for advertising or product endorsement purposes.

This work performed under the auspices of the U.S. Department of Energy by Lawrence Livermore National Laboratory under Contract DE-AC52-07NA27344. 


\title{
INVESTIGATION OF CRUSTAL MOTION IN THE TIEN SHAN USING INSAR
}

PI No. 156

Robert J. Mellors

\author{
Department of Geological Sciences, San Diego State University San Diego, CA, USA, \\ E-mail:rmellors@geology.sdsu.edu
}

\author{
Now at: Lawrence Livermore National Laboratory, Livermore, CA, USA \\ mellors1@1lnl.gov
}

\begin{abstract}
ALOS PALSAR data is used to investigate crustal motion in the Tien Shan mountains of Central Asia. As part of the work, considerable software development was undertaken to process PALSAR data. This software has been made freely available. Two damaging earthquakes have been imaged in the Tien Shan and the locations provided by ALOS InSAR have helped to refine seismological velocity models. A third earthquake south of Kyrgyzstan was also imaged. The use of InSAR data and especially L band is therefore very useful in providing groundtruth for earthquake locations.
\end{abstract}

During the project, the research was presented at three ALOS PI conferences, four other international conferences, three invited talks, one peer-reviewed article, and one student MS thesis.

\section{INTRODUCTION}

The northern Tien Shan of Central Asia is an area of active mid-continent deformation. Although far from a plate boundary, this region has experienced 5 earthquakes larger than magnitude 7 in the past century and includes one event that may as be as large as Mw 8.0. Previous studies based on GPS measurements indicate on the order of $23 \mathrm{~mm} / \mathrm{yr}$ of shortening across the entire Tien Shan and up to $15 \mathrm{~mm} /$ year in the northern Tien Shan (Figure 1). The seismic moment release rate appears comparable with the geodetic measured slip, at least to first order, suggesting that geodetic rates can be considered a proxy for accumulation rates of stress for seismic hazard estimation.

Interferometric synthetic aperture radar may provide a means to make detailed spatial measurements and hence in identifying block boundaries and assisting in seismic hazard. Therefore, we hoped to define block boundaries by direct measurement and by identifying and resolving earthquake slip.
Due to political instability in Kyrgzystan, the existing seismic network has not performed as well as required to precisely determine earthquake hypocenters in remote areas and hence InSAR is highly useful. In this paper we present the result of three earthquake studies and show that InSAR is useful for refining locations of teleseismically located earthquakes.

\section{METHODS}

The task consisted of two major stages: software development and data analysis.

2.1. Software development. As we did not have access to commercial software capable of handling ALOS data for interferometric processing, it was decided to create some initial software for reading ALOS raw data and associated information such as orbits. This was done in conjunction with Dr. David Sandwell of the University of California, San Diego [1](ALOS PI \# 114, CVST-21). Several programs were created and tested as part of am open-source, freely available generic InSAR processing package (GMTSAR):

ALOS_pre process - reformats raw data and creates a header file of information needed for the SAR processor.

ALOS_baseline - reads orbit and altitude information and calculates baselines between images.

ALOS_merge - combines two consecutive individual scenes into one large image.

$A L O S \_f b d 2 f b s$ - Resamples a raw image file in FBD mode $(14 \mathrm{MHz})$ to a sampling rate of an FBS mode (28 $\mathrm{MHz}$ ) and thereby allows interferometry between the two.

ALOS_scansar - Reads a scansar raw data file and lines of zeroes between bursts. This allows the image to be processed with a standard range doppler algorithm.

These programs are available at: 
http://topex.ucsd.edu/gmtsar/ and at the roi_pac documentation http://roipac.org/ALOS_PALSAR.

We also worked on adapting some of the programs to a GPU processor to increase speed [2]. These programs were also used as part of a pre_processor for ALOS data for the roi pac software package. Use of these programs has been widespread and we believe that it has increased the use of ALOS data. Creation of these programs was not anticipated in the original research plan and this took additional time. All work on this software was performed while the PI was at San Diego State University.

2.2 Data analysis. The initial focus was to analyze data from the North Tien Shan, a mountainous area at the northern edge of the India/Eurasia collision zone characterized by continental shortening and seismicity (Figure 1).

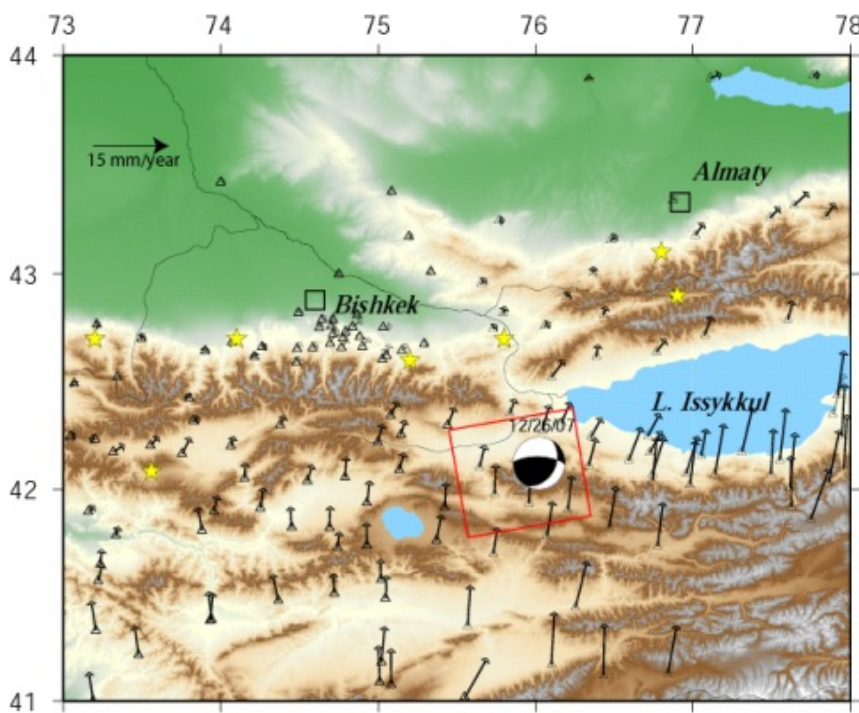

Figure 1. Map of northern Tien Shan. Arrows show showing crustal motion vectors measured by GPS. Yellow stars are historical large ( $>$ M 6.5) earthquakes and cities ( $>1$ million) are denoted by squares. The red square shows area of the ALOS PALSAR images and the focal mechanism shows the position of the 2006 Kochkorka earthquake.

We had hoped to resolve shortening but so far have been unable to clearly measure interseismic strain. This is due in part to a lack of available data with suitable baselines and repeat times due to systematic variations in the ALOS orbit.

However, in December 2006 a moderate size (M 5.8) earthquake struck Kochkorka, Kyrgyzstan [3][4][5][6]. Although not a large earthquake and centered in a remote mountain area, this moderate earthquake destroyed or damaged several thousand buildings. In October 2008, an M 6.8 event struck the isolated town of Nura, destroying the town and causing 70 deaths. We therefore decided to focus on these events as well as other in the region including an $\mathrm{M}$
6.7 in December 2010 south of Kyrgyzstan.

\section{RESULTS}

3.1 Kochkor earthquake. Two ALOS images (frame 830 path 522, ascending) acquired on 11 Nov. 2006 and on 19 February 2007 span the time and area of the earthquake with a perpendicular baseline of $95 \mathrm{~m}$.

An interferogram was calculated using the GMTSAR software. Elevation corrections were estimated using SRTM DEM. Missing pixels in the DEM in areas of high terrain gradients were interpolated to reduce artifacts and a planar trend was removed from the unwrapped interferogram.

The interferogram was compared with aftershock locations and the focal mechanism of the main shock. Aftershock locations were calculated using a double-difference algorithm. Correspondence was observed between an area of apparent uplift and the aftershocks (Figures 2 and 3). Modeling indicated that this may be due to the earthquake but required a depth of more than $5 \mathrm{~km}$. This work was the subject of an MS thesis at San Diego State.

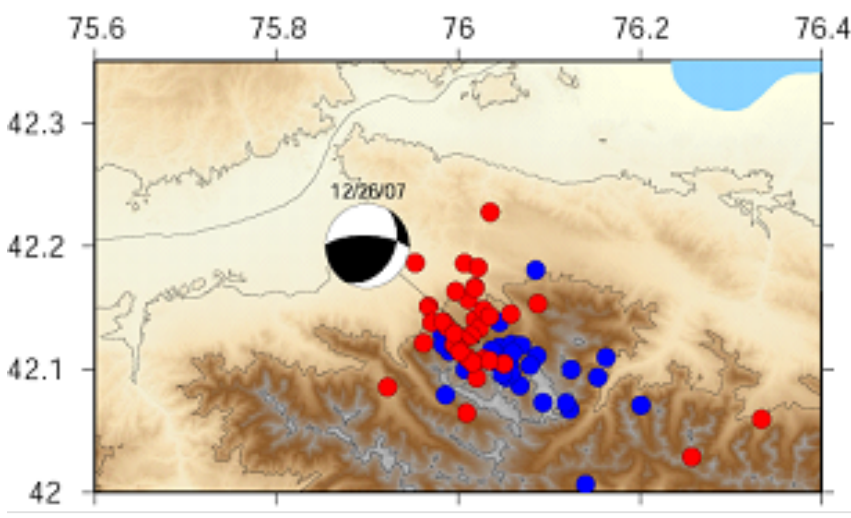

Figure 2. Focal mechanism of main shock and locations of aftershocks. Red circles represent hypocenters less than $10 \mathrm{~km}$ and blue circles represent hypocenters deeper than $10 \mathrm{~km}$. The aftershocks indicate a fault plane dipping to the southeast, which matches the orientation of known faults in the area.

\begin{tabular}{|l|l|}
\hline Latitude, longitude & $42.1,75.975$ \\
\hline Strike, dip, and slip & $30^{\circ}, 40^{\circ}, 34^{\circ}$ \\
\hline Depth (top) & $8 \mathrm{~km}$ \\
\hline Length (horizontal) & $8 \mathrm{~km}$ \\
\hline Width & $8 \mathrm{~km}$ \\
\hline Slip & $1.2 \mathrm{~m}$ \\
\hline Moment, Mw & $1.0 \times 10^{24}, \mathrm{M}_{\mathrm{w}} 5.3$ \\
\hline
\end{tabular}


Table 1. Parameters of source model for the Kochkor earthquake.

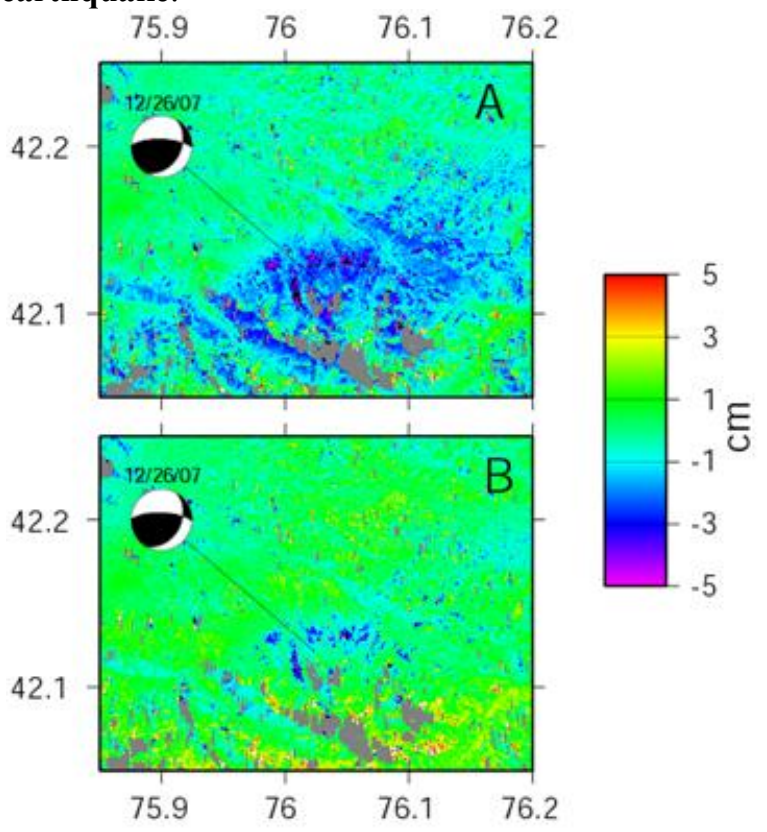

Figure 3. One possible model of line-of-sight surface deformation using the parameters in Table 1 . Aftershocks as noted in Figure 2.

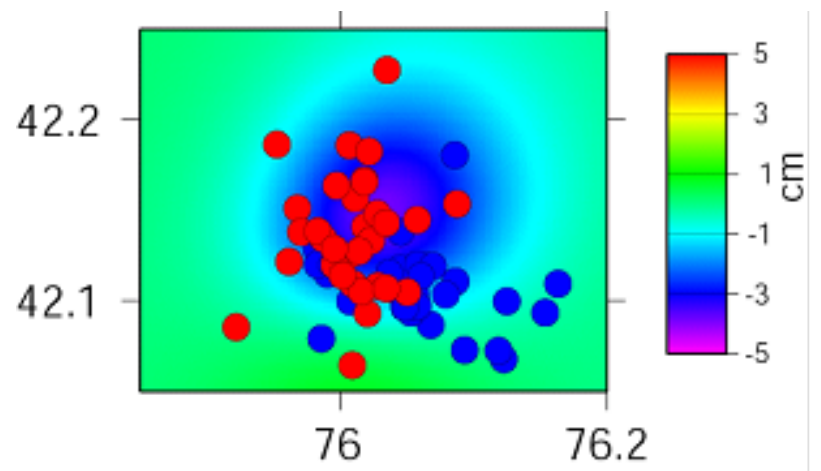

Figure 4. One possible model of line-of-sight surface deformation using the parameters in Table 1 . Aftershocks as noted in Figure 2.

3.2 Nura earthqauke. The M 6.6 earthquake struck on 5 October 2008, at Nura, Kyrgystan and caused 70 deaths $\mathrm{N}$ 39.51, $73.81 \mathrm{E}, 27 \mathrm{~km}$ (USGS NEIC location). The mechanism was a thrust fault (CMT). Comparison with the global location showed that the teleseismic location was (incorrectly) well to the south of the interferogram fringes indicating an error in the seismic location of about $20 \mathrm{~km}$. This is not unusual for this area but illustrates the use of InSAR in refining earthquake locations.

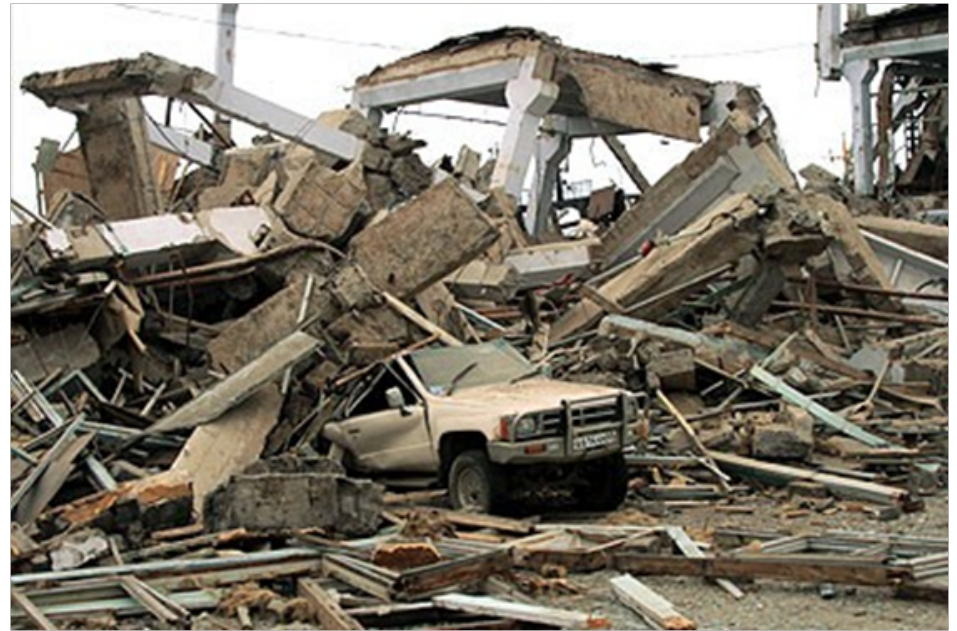

Figure 5. Picture of damage from Nura earthquake.

Courtesy www.asiannews.it

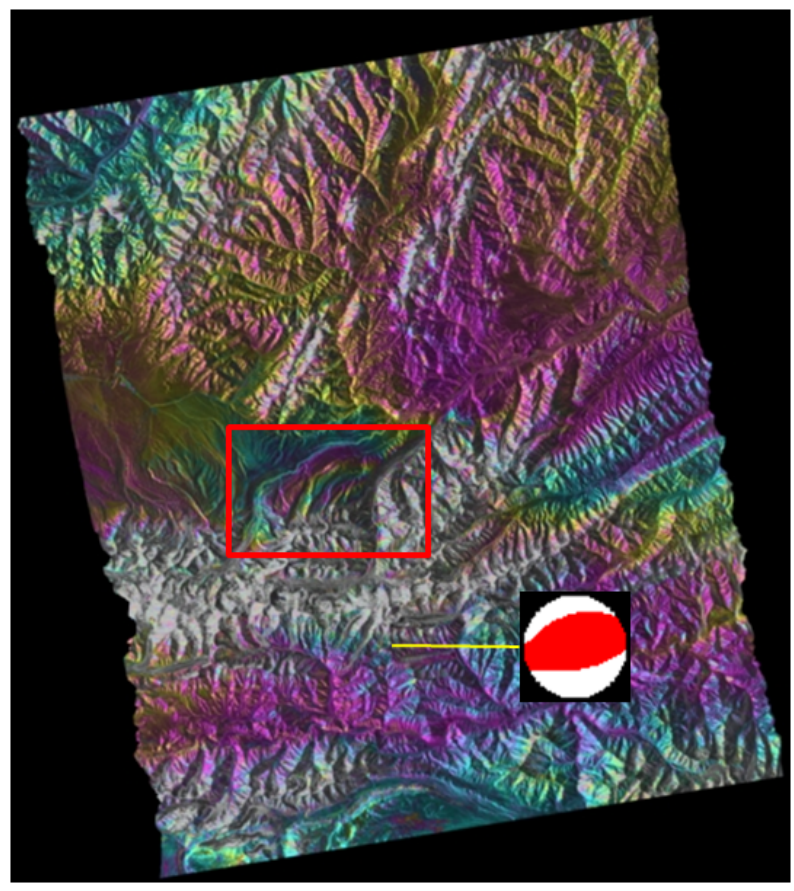

Figure 6. Interferogram of the Nura earthquake and with CMT focal mechanism. Yellow line points to the approximate (and incorrect) global location. 


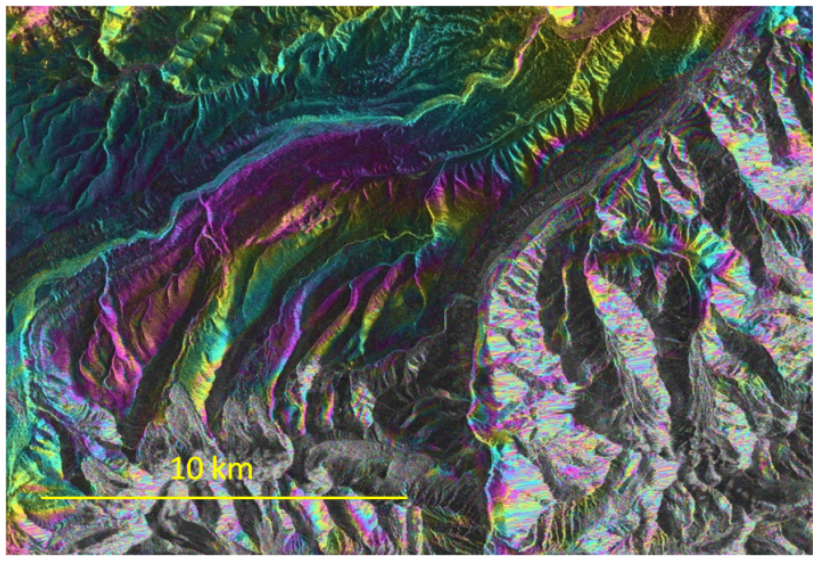

Figure 7. View of the epicentral region of the Nura earthquake.

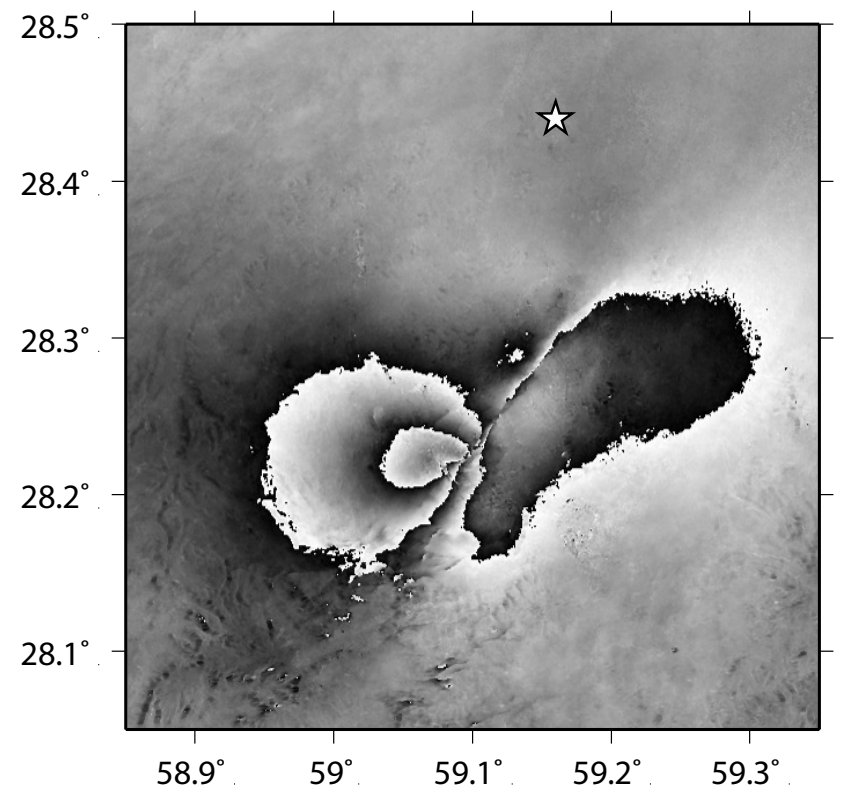

Figure 8. Interferogram of the 20 Dec 2010 event. Star indicates teleseismically determined hypocenter which is at least $20 \mathrm{~km}$ from the actual fault plane defined by the interferogram.

3.3 Earthquake of 20 Dec 2010 (Figure 8) Another clear example where InSAR data was highly useful in refining hypocentral locations. Figure 8 shows the interferogram and the NEIC location.

\section{DISCUSSION}

These earthquakes dramatically illustrate the use of InSAR in improving earthquake location. In remote areas with sparse seismic station coverage, earthquake locations of even large events can be incorrect by 10 's of $\mathrm{km}$. Therefore InSAR can provide a way to improve earthquake location by providing calibration events. It would be possible to implement a near-automatic method

\section{CONCLUSIONS}

The primary results of the work are twofold: a set of software useful for processing interferometric data and evidence that INSAR is useful for refining earthquake locations in remote regions even with limited data. It would be possible to construct a worldwide catalog of earthquakes using ALOS data if it were widely available. This type of catalog would likely lead to an increased understanding of earthquake physics and possibly reduce worldwide damage and casualties from earthquakes.

\section{REFERENCES}

[1] Sandwell, D. D. Myer, R. Mellors, M. Shimada, B. Brooks, and J. Foster, 2008, Accuracy and Resolution of ALOS Interferometry: Vector Deformation Maps of the Father's Day Intrusion at Kilauea, IEEE Transactions on Geoscience and Remote Sensing, 46, (11), 3524-3534.

[2] Mellors, R., and D. Sandwell, 2009, Using a GPU in InSAR Processing to Improve Performance, 3rd ALOS Joint PI Symposium Program, Nov. 9-13, Kona, Hawaii.

[3] Mellors, R., A. Aulia, and D. Sandwell, ALOS PALSAR interferometry in the Tien Shan: Detection of the Dec. 26, Kochkorka, Kyrgyzstan earthquake?, The First Joint PI symposium of ALOS Data Nodes for ALOS Science Program in Kyoto, Nov. 19-23, 2007.

[4] Mellors, R., A. Aulia, and Z. Kalmetyieva, The 2006 Kochkorka earthquake: a moderate but damaging event, submitted to the Seismological Society of America annual meeting, Santa Fe, New Mexico, April 15, 2008.

[5] Mellors, R. J., V. Cruz-Atienza, A. Aulia, and Z. Kalmetyeva, 2008, Modeling the 2006 Kochkor, Kyrgyzstan earthquake and waveform propagation in the northern Tien Shan, Proceedings of the Fourth International Symposium, Geodynamics of Intracontinental Orogens, Bishkek, Kyrgzystan, 15-23 June.

[6] Arifandy, A., Seismic Hazard Analysis of Kyrgyzstan using Data from the 2006 MW 5.8 Kochkor Earthquake, M.S. thesis, San Diego State University, 70 p. 